\section{Comment}

Two thirds of families gave telephone consent to blood, lymph node, and liver samples being taken at postmortem examination and used as control samples in a study designed to validate tests for viral markers. The negative effect of media attention on postmortem retention of organ and tissues was small. The results compare with a $98.8 \%$ consent rate for use of surplus tissue in research among surgical patients from the same hospital trust. ${ }^{3}$ These findings reinforce the notion that attitudes about using tissue from dead people are different from those about tissue from the living.

The attitudes of recently bereaved families in our study are similar to those described in qualitative research published by the Retained Organs Commission. ${ }^{4}$ The commission's research found that most of the public support use of postmortem material for medical purposes and identified consent as an issue. A review from the NHS Centre for Reviews and Dissemination concludes that few data are suitable for inclusion in a systematic review of the psychological aspects of organ and tissue donation and suggests that primary research is a more suitable option. ${ }^{5}$

Funding: The viral markers study was funded by the Department of Health through the National Institute for Biological Standards and Controls.
Contributors: CW participated in the design of the study, collation of the results, and writing the report. ALJ did most of the interviews and participated in the design and collation of results. $\mathrm{CW}$ is the guarantor.

Competing interests: Peterborough Hospitals NHS Trust and commercial and academic clients stand to gain financially from research using human issue, although not from this study. CW is a member of the medical advisory board of Pathlore, which is responsible for processing tissue for the tissue bank and has done paid consultancy work for Capio, Pharmogene, Celltech, and Medical Solutions. CW and ALJ have received expenses and occasionaly fees for presentations and CW has received travel sponsorship to a meeting from GlaxoSmithKleine.

Ethical approval: The study was approved by Peterborough and Fenland local research ethics committee.

Padley DJ, Lucas SB, Saldanha J. Elimination of false negative HCV RNA results by removal of inhibitors in cadaver organ donor blood specimens. Transplantation 2003;76:432-4.

2 Womack C, Gray NM, Pearson JE, Fehily D. Cadaveric tissue supply to the commercial sector for research: collaboration between NHS pathology and NBS Tissue Services extending the options for donors. Cell Tissue Banking 2001:2:51-5.

Banking 2001;2:51-5.
Jack AL, Womack C. Why surgical patients do not donate tissue for commercial research: review of records. BMJ 2003;327:262.

Retained Organs Commission. Qualitative research to explore public perceptions regarding retention of organs and tissue for medical practice, teaching and research. www.nhs.uk/retainedorgans/trrep.pdf practice, teaching and

5 Forbes C, Glanville J, Kleijnen J. Psychological aspects of organ and tissue retention: a scoping review. www.doh.gov.uk/tissue/scopingreview.pdf (accessed 4 May 2003).

(Accepted 3 July 2003)

\title{
British hospitals and different versions of the Glasgow coma scale: telephone survey
}

Martin F Wiese

King's College Hospital, London SE5 9RS

Martin F Wiese specialist registrar in emergency medicine

Correspondence to: wiese@doctors.org.uk

BMJ 2003;327:782-3
The Glasgow coma scale is a clinical scoring system for objectively assessing how conscious a patient is. Although limited for predicting functional outcome, ${ }^{1}$ the scale is useful when making decisions about management in the acute setting, particularly for patients with traumatic brain injuries. Patients who score $<15$ need imaging or observation, and patients with scores $<9$ need to be promptly considered for definitive airways management.

The original Glasgow coma scale, published in 1974, had 14 points. ${ }^{2}$ Two years later, its authors introduced a distinction between "normal" and "abnormal" flexion (withdrawal to pain and decorticate response) increasing the "best motor response" item by one point. ${ }^{3}$ This revised scale is central to important clinical guidelines and has been the accepted version for more than 25 years. $^{4}$

Nevertheless, anecdotal evidence suggests that neurological observation charts based on the original 14 point scale are still being used in British hospitals. This study establishes the prevalence of this practice because it carries the potential for errors in communication and conflict with guidelines.

\section{Participants, methods, and results}

I conducted a national observational study of the neurological observation charts used in hospitals which care for adult patients with traumatic brain injuries.

Using the 2001-2 directory of the British Association for Accident and Emergency Medicine, I identified all UK emergency departments which manage patients with traumatic brain injuries. We contacted a sister or charge nurse in each departments. Using a structured telephone interview, we asked staff to determine which version of the Glasgow coma scale they used by checking the neurological observation chart visually. We also asked the nurse to name one ward providing observation for patients with traumatic brain injuries, where we repeated the interview. Finally, we telephoned one ward in every specialist neurosurgical unit in the United Kingdom (table).

\section{Comment}

The original, 14 point, Glasgow coma scale continues to be used in many British hospital units which manage patients with traumatic brain injuries. Many of the staff that we contacted were not aware that the version of the scale that they were using had been superseded.

The parallel use of two versions of the Glasgow coma scale in the United Kingdom has been virtually unnoticed, possibly because publication of the revised 
Version of the Glasgow coma scale on neurological observation charts in UK hospitals managing patients with traumatic brain injuries. Values are numbers (percentage)

\begin{tabular}{|c|c|c|c|c|}
\hline \multirow[b]{2}{*}{$\begin{array}{l}\text { Version of Glasgow coma } \\
\text { scale (points) }\end{array}$} & \multirow[b]{2}{*}{$\begin{array}{l}\text { Emergency departments } \\
\qquad(\mathrm{n}=233)\end{array}$} & \multicolumn{2}{|c|}{ Wards for observing patients with traumatic brain injuries $(\mathrm{n}=233)$} & \multirow[b]{2}{*}{$\begin{array}{l}\text { Neurosurgical units } \\
(\mathrm{n}=32)\end{array}$} \\
\hline & & $\begin{array}{l}\text { Emergency department observation } \\
\text { wards ( } \mathrm{n}=58)\end{array}$ & Other* $(n=175)$ & \\
\hline 15 & $178(76.4)$ & $41(70.7)$ & $90(51.4)$ & $18(56.3)$ \\
\hline 14 & 55 (23.6) & $17(29.3)$ & $81(46.3)$ & $13(40.6)$ \\
\hline Not used & 0 & 0 & $4(2.3)$ & $1(3.1)$ \\
\hline
\end{tabular}

${ }^{*}$ Only about a quarter of all emergency departments have their own observation ward. In most British hospitals, patients with traumatic brain injuries are admitted to general surgical or orthopaedic wards. More rarely, patients are observed on medical, otorhinolaryngological, or neurosurgical wards.

scale in 1976 was not accompanied by an explanation and did not result in a clarifying change of name.

No evidence has been published that the continued use of the 14 point scale may have caused harm to any patient. The practice does, however, lead to difficulties. Staff from one hospital told us about their recurrent problems communicating with the local neurosurgical unit because the two were using different scales. In another trust, the neurological observation charts were changed after a recent coroner's inquest: relatives of a patient who had died of severe traumatic brain injury had raised questions about the logic of two different versions of the Glasgow coma scale being used within the same trust.

Users of the Glasgow coma scale need training to ensure consistency and reliability of scoring. ${ }^{5}$ The continued employment of two different scales can only add to the confusion. Although the 15 point Glasgow coma scale is not perfect, it should be used by everybody who manages patients with traumatic brain injuries until even better measures of consciousness are devised.

I thank D Wallis for help with the study design and E Glucksman and P Leman for their comments on the drafts. Many thanks also to all the hospital staff.

Contributors: MFW wrote the paper and is guarantor. Nicola Burger collected some data.

Funding: None.

Competing interests: None declared.

1 Diringer MN, Edwards DF. Does modification of the Innsbruck and the Glasgow Coma Scales improve their ability to predict functional outcome? Arch Neurol 1997;54:606-11.

2 Teasdale GM, Jennett B. Assessment of coma and impaired consciousness: a practical scale. Lancet 1974;2:81-4.

Teasdale GM, Jennett B. Assessment and prognosis of coma after head injury. Acta Neurochir (Wien) 1976;34:45-55.

American College of Surgeons Committee on Trauma. Advanced trauma life support student manual. 6th ed. Chicago: ACS, 1997.

5 Lenfant F, Sobraques P, Nicolas F, Combes JC, Honnart D, Freysz M. Use Lenfant F, Sobraques P, Nicolas F, Combes JC, Honnart D, Freysz M. Use
of Glasgow coma scale by anesthesia and intensive care internists in brain injured patients. Ann Fr Anesth Reanim 1997;16:239-43. (In French.)

(Accepted 3 July 2003)

\title{
Substance misuse in psychiatric inpatients: comparison of a screening questionnaire survey with case notes
}

\author{
Ben Barnaby, Colin Drummond, Annie McCloud, Tom Burns, Nicola Omu
}

Doctors are poor at taking alcohol histories in many clinical settings. ${ }^{12}$ Given the increasing prevalence of drug misuse in the general population and in psychiatric patients, the extent of detection of drug misuse is also important. For patients with comorbid substance misuse and psychiatric problems, the UK Department of Health states, "Individuals with dual problems deserve high quality, patient focused, and integrated care. This should be delivered within mental health services." If substance misuse is not detected, however, such care is unlikely to be delivered. We examined data to investigate the prevalence of alcohol and drug misuse in inpatients admitted to psychiatric wards and the extent and accuracy of detection by the psychiatrists doing assessments on admission.

\section{Participants, methods, and results}

We aimed to approach all new admissions to six acute psychiatric wards in two London hospitals over three months. Patients who consented completed the alcohol use disorders identification test (AUDIT) and a short version of the substance abuse assessment questionnaire. ${ }^{4}$ An AUDIT score $\geq 8$ indicates hazardous alcohol use and $\geq 15$ indicates alcohol dependence.
We excluded patients who did not speak English, who were admitted to the psychiatric intensive care unit, or who were younger than 18 or older than 75 . We also excluded patients admitted to specialist wards for addiction or eating disorders and those admitted to forensic wards.

We studied case notes to determine whether a history of substance misuse had been recorded on current admission, its comprehensiveness, whether relevant investigations had been performed, and whether any screening tools had been completed. We considered alcohol and illicit drugs separately. A full history was one including the age of first misuse of each substance, and questions about problems related to using substances and symptoms of dependence, periods of abstinence, and use of specialist services. A partial history contained any one or more of these but less than a full history.

Of a total of 364 new admissions, 326 (89\%) were eligible; we approached 263 patients, and 200 (76\% of those eligible) gave consent. Not seeing patients was usually because they were admitted and discharged over a weekend or because they absconded.

Of the 200 patients who took part, 106 (53\%) were men and $94(47 \%)$ were women. Mean age was 41 years; 